\title{
Association of interferon regulatory factor 4 gene polymorphisms rs12203592 and rs872071 with skin cancer and haematological malignancies susceptibility: a meta-analysis of 19 case-control studies
}

Songtao Wang ${ }^{1 \dagger}$, Qing Yan $^{1+}$, Pin Chen ${ }^{1}$, Peng Zhao ${ }^{1 *}$ and Aihua $\mathrm{Gu}^{2,3^{*}}$

\begin{abstract}
Background: Research has indicated that the rs12203592 and rs872071 interferon regulatory factor 4 (IRF4) gene polymorphisms correlate with the risk of cancer, especially skin cancer and haematological malignancies, but the results remain controversial. To understand better the effects of these two polymorphisms on skin cancer and haematological malignancies susceptibility, a cumulative meta-analysis was performed.

Methods: We conducted a search using the PubMed and Web of Science databases for relevant case-control studies published before April 2014. Summary odds ratios (ORs) and corresponding 95\% confidence intervals (Cls) were estimated using fixed- or random-effects models where appropriate. Heterogeneity test, publication bias test, and sensitivity analysis were also performed.

Results: In total, 11 articles comprised of 19 case-control studies were identified; five focused on the rs 12203592 polymorphism with 7,992 cases and 8,849 controls, and six were on the rs872071 polymorphism with 3108 cases and 8300 controls. As for rs12203592, a significant correlation with overall skin cancer and haematological malignancies risk was found with the homozygote comparison model $(\mathrm{OR}=1.566,95 \% \mathrm{Cl} 1.087-2.256)$ and recessive model $(\mathrm{OR}=1.526,95 \% \mathrm{Cl} 1.107-2.104)$. For $\mathrm{rs} 872071$, a significantly elevated haematological malignancies risk was observed in all genetic models (homozygote comparison: $\mathrm{OR}=1.805,95 \% \mathrm{Cl} 1.402-2.323$; heterozygote comparison: $\mathrm{OR}=1.427,95 \% \mathrm{Cl} 1.203-1.692$; dominant: $\mathrm{OR}=1.556,95 \% \mathrm{Cl} 1.281-1.891$; recessive: $\mathrm{OR}=1.432,95 \% \mathrm{Cl}$ 1.293-1.587; additive: $\mathrm{OR}=1.349,95 \% \mathrm{Cl} 1.201-1.515)$. Similarly, increased skin cancer and haematological malignancies risk was also identified after stratification of the SNP data by cancer type, ethnicity and source of controls for both polymorphisms.

Conclusions: Our meta-analysis indicated that the rs12203592 and rs872071 IRF4 gene polymorphisms are associated with individual susceptibility to skin cancer and haematological malignancies. Moreover, the effect of the rs12203592 polymorphism on skin cancer risk was particularly prominent among Caucasians. Further functional research should be performed to validate the association.
\end{abstract}

Keywords: Meta-analysis, IRF4, Interferon regulatory factor 4, Polymorphisms, rs12203592, rs872071, Cancer risk

\footnotetext{
* Correspondence: zhaopeng@njmu.edu.cn; aihuagu@njmu.edu.cn

${ }^{\dagger}$ Equal contributors

'Department of Neurosurgery, The First Affiliated Hospital, Nanjing Medical

University, Nanjing, China

${ }^{2}$ State Key Laboratory of Reproductive Medicine, Institute of Toxicology,

Nanjing Medical University, Nanjing, China

Full list of author information is available at the end of the article
} 


\section{Background}

Cancer is a multifactorial disease resulting from complex interactions between environmental and genetic factors. Cancer is one of the leading causes of death worldwide $[1,2]$. Skin cancer is the most common carcinoma, affecting millions worldwide [3]. The two major groups of skin cancer are non-melanoma and melanoma. The most common type of non-melanoma skin cancer is basal cell carcinoma (BCC) followed by squamous cell carcinoma (SCC). Melanoma is a malignant tumour of melanocytes. Melanoma can occur in any part of the body and is thought to be the most fatal form of skin cancer [4-7].

Haematological malignancies, including leukaemia, lymphoma and plasma cell dyscrasia, are a group of disorders that affect blood, bone marrow, lymph nodes and spleen. These malignancies make up approximately 9.5\% of all new cancer diagnoses in the United States $[8,9]$. Haematological malignancies, such as chronic lymphocytic leukaemia (CLL), multiple myeloma(MM), Hodgkin lymphoma (HL) and non-Hodgkin lymphoma (NHL), are derived from lymphocyte cells $[10,11]$. Among these neoplasms, CLL is the most common form of lymphoid malignancy in Western countries [12]; malignant lymphoma, generally divided into HL and NHL, is the most common haematological malignancy in the world. MM is a malignancy of plasma cells with a complex aetiology $[13,14]$. However, the exact mechanism of carcinogenesis remains unclear. In recent years, evidence has revealed that genetic variation can modulate several important biological processes, thereby altering cancer susceptibility.

Interferon regulatory factors (IRF) are a family of transcription factors characterised by a DNA-binding domain containing a five-tryptophan residue repeat $[15,16]$. IRFs are widely expressed and regulate not only the cellular response to interferons but also cell growth, susceptibility to transformation by oncogenes, induction of apoptosis, and the development of the T-cell immune response [17]. The IRF family contains at least ten proteins that modulate the expression of interferon-inducible genes, considered to play an important role in the immune response and tumorigenesis $[15,18,19]$. As a member of the IRF family of transcription factors, IRF4 (also known as multiple myeloma 1 (MUM1) and lymphocyte-specific interferon regulatory factor (LSIRF)) is expressed in most cell types of the immune system [20,21]. Recently, IRF4 was reported to be essential to the development and function of $\mathrm{T}$ helper (Th) cells, regulatory $\mathrm{T}$ (Treg) cells, B cells and dendritic cells $[22,23]$. Research has demonstrated that IRF4 plays a pivotal role in the development and progression of cancer, particularly in skin cancer and haematopoietic malignancies $[22,24]$.

Genome-wide association studies (GWAS) are the ideal strategy to select common, low-penetrance susceptibility loci without prior hypotheses about the role of the genes in disease development. Recent GWAS have reported that variants at several sites within the IRF4 gene may be implicated in the risk of cancer. Most importantly, the intron 4 SNP rs12203592 and 3' UTR SNP rs872071 are associated with an increased risk for melanoma, BCC [25,26], CLL and MM [27,28]. Given that the IRF4 gene has been recognised as one of the most common tumour markers, numerous studies have assessed the possible association between the IRF4 polymorphisms and cancer risk. However, the results are inconclusive. To derive a more precise estimation of the relationship between the rs12203592 and rs872071 IRF4 polymorphisms and cancer risk, we performed a metaanalysis of all available case-control studies.

\section{Methods}

\section{Literature search strategy}

We searched the PubMed and Web of Science databases for all relevant articles regarding IRF4 SNPs associated with cancer risk (search last updated on April 10, 2014). The following keywords were used: "IRF4" or "interferon regulatory factor 4", "polymorphisms or variant or SNP or mutation" and "cancer or tumor or neoplasm or carcinoma". The search was conducted exclusively on human subjects. The reference lists of reviews and retrieved articles were simultaneously hand-searched. We did not consider abstracts or unpublished reports.

\section{Inclusion criteria}

All abstracts of citations and retrieved studies were reviewed. The following criteria were used to identify eligible published studies: (i) the study evaluated the association between the IRF4 polymorphisms (rs12203592 and rs872071) and cancer risk; (ii) the publication was a case-control or case-cohort study; (iii) the paper provided sample size, distribution of alleles, genotypes or other information that can help us estimate an OR with 95\% confidence interval (95\% CI); (iv) the genotype distribution of the control population is consistent with Hardy-Weinberg Equilibrium (HWE). Accordingly, publications were excluded using the following criteria: (i) articles that were not about cancer research; (ii) the publication contained duplicated previous research; (iii) the study did not include usable genotype data were excluded.

\section{Data extraction}

Two investigators independently extracted information from all eligible publications according to the inclusion criteria listed above. The results were compared, and disagreements were resolved by discussion until a consensus was reached. Data extracted from each study included the following characteristics: the first author's name, the year of publication, the country of participants, ethnicity, cancer type, source of control group 
(population- or hospital-based controls), and the genotype frequency of the rs12203592 and rs872071 polymorphism in the cases and controls.

\section{Statistical analysis}

All statistical analysis was performed using STATA software (version 11.0; STATA Corporation, College Station, TX). Two sided P-values $<0.05$ were considered statistically significant. Our meta-analysis recalculated HWE in the controls for each study. The goodness of fit test (chisquare or Fisher's exact test) was used to assess deviation from HWE (significant at the 0.05 level). Studies that deviated from $\mathrm{HWE}$ were removed.

ORs with 95\% CIs were used to estimate the strength of the association between the IRF4 rs12203592 and rs872071 polymorphisms and skin cancer and haematopoietic malignancies risk. In addition, the Z-test was also used, and a $P$ value $<0.05$ indicated statistical significance for the association. We examined the association between the rs12203592 IRF4 polymorphism and skin cancer and haematopoietic malignancies using the homozygote comparison (TT versus $\mathrm{CC}$ ), heterozygote comparison (CT versus $\mathrm{CC}$ ), dominant genetic model ( $\mathrm{TT}+\mathrm{CT}$ versus $\mathrm{CC}$ ), recessive genetic model (TT versus $\mathrm{CT}+\mathrm{CC}$ ) and additive genetic model ( $\mathrm{T}$ versus $\mathrm{C}$ ). The same methods were applied to the analysis of the rs872071 IRF4 polymorphism. In addition, a stratified analysis was also performed based on cancer type, ethnicity and the source of controls.

The assumption of heterogeneity was ascertained using a chi-based Q-test. A P-value less than 0.05 for the Q test indicated significant heterogeneity among the studies. The pooled OR was estimated using a fixed- or random-effects model, where appropriate. If the $\mathrm{P}$ value was less than 0.05 indicative of heterogeneity across studies, a randomeffects model (DerSimonian and Laird) was utilised for the meta-analysis [29]. Otherwise, a fixed-effect model (Mantel-Haenszel) was used [30]. We also quantified the effect of heterogeneity using the $I^{2}$ test. $I^{2}$ values of 25, 50, and $75 \%$ were indicative of low, moderate, and high heterogeneity, respectively.

The sensitivity analysis was conducted by removing one study at a time to evaluate the quality and consistency of the meta-analysis results. Publication bias was qualitatively and quantitatively assessed using the Begg's funnel plots and Egger's test, respectively [31]. To ensure the reliability and the accuracy of the results, two reviewers independently assessed the data using the statistical software programmes and obtained the same results.

\section{Results}

\section{Literature search and characteristics}

A total of 179 potential individual publications were initially identified after a systematic literature search of the
PubMed, Embase and Web of Science databases. The titles, abstracts and full texts of the retrieved articles were reviewed based on the inclusion criteria shown in Figure 1. Finally, we identified 11 eligible articles comprised of 19 studies for the current meta-analysis [24,27,32-40]. In all the eligible articles, studies by Han et al., Wang et al., Broderick et al., Di Bernardo et al. include different sets of data, and each set of data was treated as a separate case-control study in this metaanalysis (Table 1). Our meta-analysis included 11 of the rs12203592 polymorphism with 7,992 cases and 8,849 controls and 8 studies of the rs 872071 polymorphism with 3108 cases and 8300 controls. All studies were published in English. The control genotype distributions of all studies were in accordance with HWE. Detailed study characteristics included in the current meta-analysis are presented in Table 1.

\section{Quantitative assessment of the included studies}

A summary of the meta-analysis findings on the association between the rs12203592 and rs872071 IRF4 polymorphisms and skin cancer and haematopoietic malignancies risk is presented in Table 2. With respect to the rs12203592 polymorphism, a total of 11 studies from 5 articles were included in this meta-analysis. Among the 11 studies, 8 focused on skin cancer and 3 on NHL. Eight studies used Caucasian populations, and 3 were from USA with mixed ethnicity. Four studies used population-based controls, and 7 used hospital-based controls. The overall analyses suggested a significant association between the rs12203592 polymorphism and skin cancer and haematopoietic malignancies susceptibility in the homozygote comparison model $(\mathrm{OR}=1.566,95 \%$ CI 1.087-2.256) and recessive model $(\mathrm{OR}=1.526,95 \%$ CI $1.107-2.104$, Figure 2a) using the random-effects model. The results from the other genetic models were not significant. Specific data for the rs12203592 polymorphism were stratified by cancer type into the NHL subgroup or the skin cancer subgroup (melanoma, BBC and SCC). For skin cancer, a significantly increased risk was observed using the homozygote comparison model $(\mathrm{OR}=1.728,95 \% \mathrm{CI}$ $1.145-2.608)$ and recessive model $(\mathrm{OR}=1.808,95 \% \mathrm{CI}$ 1.127-2.900). However, no significant association was observed in the NHL subgroup. In the subgroup analysis stratified by ethnicity, a significantly elevated cancer risk was found among Caucasians with the homozygote comparison model $(\mathrm{OR}=1.566$, 95\% CI $1.087-2.256)$ and recessive model $(\mathrm{OR}=1.526,95 \% \mathrm{CI}$ 1.107-2.104) but not among Asian populations with all genetic models. When stratified by the source of controls, a significantly increased risk was observed in the hospital-based studies under four genetic models (homozygote comparison: $\mathrm{OR}=2.094,95 \%$ CI 1.314-3.336; dominant genetic model: $\mathrm{OR}=1.314,95 \%$ CI 1.002-1.723; 


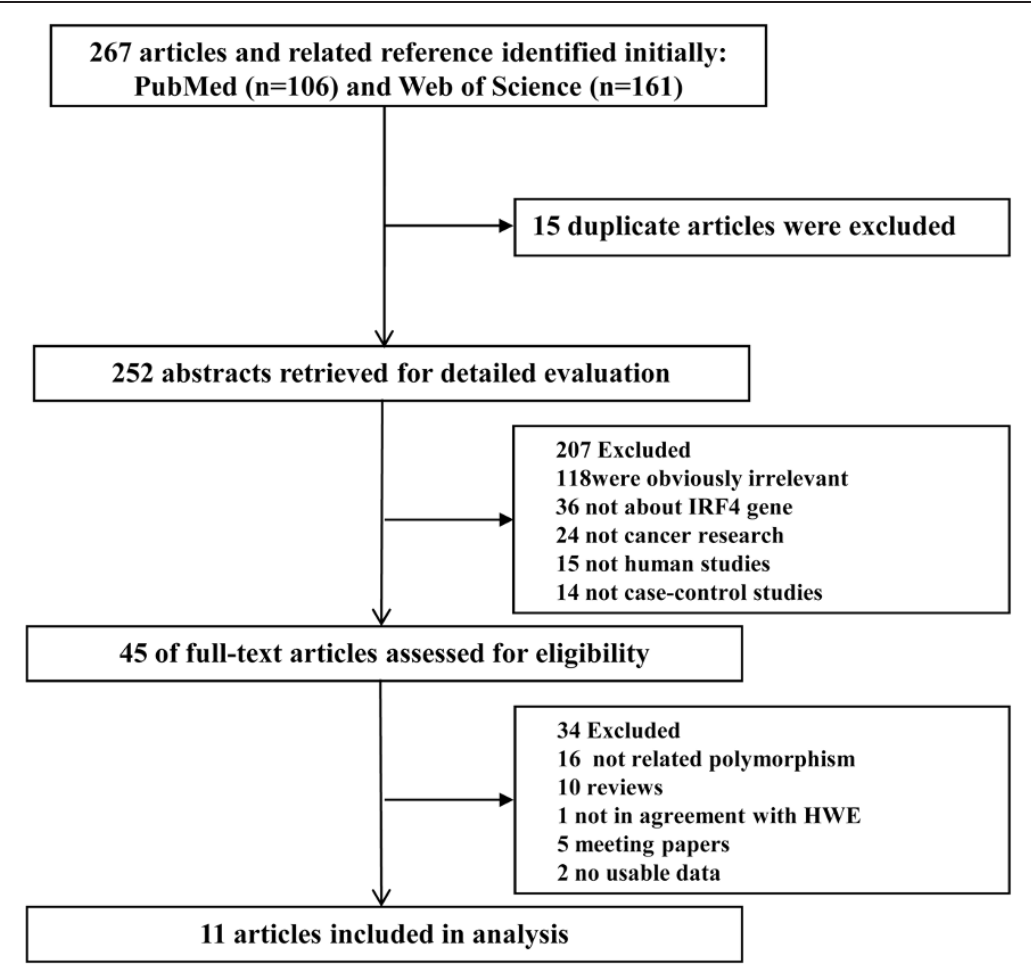

Figure 1 Flow chart of literature search and study selection.

recessive genetic model: $\mathrm{OR}=1.959,95 \%$ CI 1.310-2.931; additive model OR $=1.35$, 95\%CI 1.058 -1.725), whereas no significant association was observed in the populationbased studies for all five genetic models.

With respect to the rs872071 polymorphism, a total of 8 studies from 6 articles were included. Of the 8 eligible studies, 4 focused exclusively on CLL, 3 on lymphoma and 1 on MM. Caucasian populations were used in 6 studies, and Asians were assessed in 2. Five of the studies were population-based controls, and 3 used hospitalbased controls. Overall, a significantly elevated haematological malignancies risk was associated with the rs872071 polymorphism in all genetic models (homozygote comparison: $\mathrm{OR}=1.805,95 \%$ CI 1.402-2.323; heterozygote comparison: $\mathrm{OR}=1.427$, 95\% CI 1.203-1.692; dominant: $\mathrm{OR}=1.556,95 \%$ CI 1.281-1.89; recessive: $\mathrm{OR}=1.432,95 \%$ CI 1.293-1.587, Figure 2b; additive: $\mathrm{OR}=1.349,95 \% \mathrm{CI}$ 1.201-1.515). After stratification by cancer type (HL and NHL were merged as lymphoma) and source of controls, a significant association was also observed with all of the genetic models. When we stratified the studies by ethnicity, a significant association was also observed in Caucasians under all genetic models. In Asians, the association was significant in all genetic models except for the recessive genetic model $(\mathrm{OR}=1.233$, 95\% CI 0.924 1.646). The meta-analysis results for the subgroups are listed in Table 2.

\section{Test of heterogeneity}

For the rs12203592 polymorphism, all genetic models showed significant heterogeneity. After subgroup analysis by cancer type, the heterogeneity was effectively removed in the NHL subgroup. In the analysis of ethnicity, the heterogeneity significantly disappeared in the mixed subgroup. When stratified based on the source of controls, the heterogeneity also disappeared in the populationbased control subgroups. The heterogeneity values are presented in Table 2.

Significant heterogeneities were observed in the overall analysis of the association between the rs872071 polymorphism and haematological malignancies risk in four genetic models (homozygote comparison, heterozygote comparison, dominant genetic model and additive model). After subgroup analysis by cancer type, the heterogeneity effectively disappeared in the CLL subgroup and lymphoma subgroup. In the analysis of ethnicity, the heterogeneity was significantly removed in the Asian population but remained in the Caucasians. When stratified based on the source of controls, heterogeneity was not observed in the hospital-based control subgroups. The heterogeneity values are presented in Table 2.

\section{Publication bias and sensitivity analysis}

Publication biases of the literature were investigated using the Begg's funnel plot and Egger's test. With respect to the 
Table 1 Main characteristics of all studies included in the meta-analysis

\begin{tabular}{|c|c|c|c|c|c|c|c|c|c|c|c|c|}
\hline rs12203592 & & & & & & Case & & & Control & & & \\
\hline First author & Year & Country & Ethnicity & Cancer type & Source of controls & $\mathrm{CC}$ & TC & $\mathrm{TT}$ & CC & $\mathrm{TC}$ & $\mathrm{TT}$ & HWE \\
\hline Gathany [24] & 2009 & USA & Mixed & $\mathrm{NHL}$ & PB & 730 & 239 & 19 & 605 & 202 & 18 & 0.814 \\
\hline Wang 1 [40] & 2009 & USA & Mixed & $\mathrm{NHL}$ & PB & 299 & 123 & 13 & 357 & 143 & 15 & 0.882 \\
\hline Wang 2 [40] & 2009 & USA & Mixed & $\mathrm{NHL}$ & PB & 332 & 157 & 29 & 283 & 160 & 19 & 0.541 \\
\hline Kvaskoff [34] & 2011 & France & Caucasians & Melanoma & $\mathrm{HB}$ & 654 & 307 & 48 & 871 & 518 & 79 & 0.862 \\
\hline Han 1 [35] & 2011 & USA & Caucasians & Melanoma & $\mathrm{HB}$ & 123 & 54 & 11 & 450 & 163 & 19 & 0.369 \\
\hline Han 2 [35] & 2011 & USA & Caucasians & Melanoma & $H B$ & 126 & 68 & 20 & 565 & 232 & 29 & 0.394 \\
\hline Pena-Chilet [32] & 2013 & Spain & Caucasians & Melanoma & PB & 398 & 121 & 19 & 242 & 101 & 19 & 0.055 \\
\hline Han 3 [35] & 2011 & USA & Caucasians & SCC & $\mathrm{HB}$ & 156 & 80 & 15 & 450 & 163 & 19 & 0.369 \\
\hline Han 4 [35] & 2011 & USA & Caucasians & SCC & $H B$ & 143 & 110 & 20 & 565 & 232 & 29 & 0.394 \\
\hline Han 5 [35] & 2011 & USA & Caucasians & $\mathrm{BCC}$ & $\mathrm{HB}$ & 139 & 54 & 20 & 503 & 191 & 24 & 0.269 \\
\hline Han 6 [35] & 2011 & USA & Caucasians & $\mathrm{BCC}$ & $H B$ & 174 & 81 & 19 & 565 & 232 & 29 & 0.394 \\
\hline rs872071 & & & & & & Case & & & Control & & & \\
\hline First author & Year & Country & Ethnicity & Cancer type & Source of controls & AA & AG & GG & AA & AG & GG & HWE \\
\hline Di Bernardo 1 [27] & 2008 & UK & Caucasians & CLL & $\mathrm{HB}$ & 63 & 248 & 190 & 305 & 720 & 411 & 0.754 \\
\hline Di Bernardo 2 [27] & 2008 & UK & Caucasians & CLL & PB & 67 & 232 & 201 & 183 & 391 & 202 & 0.816 \\
\hline Lan [36] & 2010 & USA & Asians & $C L L$ & $H B$ & 21 & 36 & 12 & 602 & 534 & 127 & 0.978 \\
\hline Crowther-Swanepoel [37] & 2010 & UK & Caucasians & CLL & PB & 74 & 203 & 117 & 129 & 179 & 89 & 0.076 \\
\hline Broderick 1 [39] & 2010 & UK & Caucasians & $\mathrm{HL}$ & PB & 16 & 55 & 36 & 228 & 519 & 278 & 0.629 \\
\hline Broderick 2 [39] & 2010 & UK & Caucasians & $\mathrm{HL}$ & PB & 83 & 198 & 118 & 259 & 562 & 269 & 0.302 \\
\hline Pratt [38] & 2010 & UK & Caucasians & MM & PB & 82 & 169 & 101 & 183 & 388 & 200 & 0.846 \\
\hline Qiao [33] & 2013 & China & Asians & $\mathrm{NHL}$ & $\mathrm{HB}$ & 341 & 381 & 64 & 777 & 653 & 112 & 0.112 \\
\hline
\end{tabular}

BCC: Basal cell carcinoma; SCC: Squamous cell carcinoma; HL: Hodgkin lymphoma; NHL: Non-Hodgkin lymphoma; MM: Multiple myeloma; CLL: Chronic lymphocytic leukaemia.

$P B$ : population based; $H B$ : hospital based.

HWE: Hardy-Weinberg equilibrium.

rs12203592 polymorphism, the results of the Begg's funnel plot suggested no publication bias. The Egger's test did not show statistical evidence for publication bias (homozygote comparison model: $t=1.38, \mathrm{P}=0.201$ ). The shapes of the funnel plots did not reveal any evidence of obvious asymmetry for the rs 872071 polymorphism with all genetic models (Figure not shown). Similarly, the results of the Egger's test indicated a lack of publication bias (homozygote comparison model: $\mathrm{t}=0.61, \mathrm{P}=0.556$ ).

Sensitivity analyses were also performed in the current meta-analysis to assess the influence of each individual study on the pooled ORs by sequential removal of individual studies. For both the rs12203592 and rs872071 polymorphisms in the IRF4 gene, the results suggested that no individual study significantly altered the pooled results, thereby suggesting that the results of this metaanalysis are robust and reliable (Figure $3 \mathrm{a}$ and $3 \mathrm{~b}$ ).

\section{Discussion}

IRF4, a member of the IRF family of transcription factors, is expressed in cells of the immune system and transduces signals from various receptors to activate or suppress gene expression [15,41]. The product of the IRF4 gene is confined to cells of the immune system and melanocytic lineages [42]. It is considered a key regulator of several steps in lymphoid-, myeloid-, and dendritic-cell differentiation. It promotes the differentiation of mature B cells into antibody-secreting plasma cells $[43,44]$. Additionally, research has revealed that the IRF4 protein is expressed in a wide spectrum of haematological malignancies and skin cancers [42,45]. IRF4 plays an important role in cancer pathogenesis and acts as a potential marker for haematological neoplasms and malignant melanoma [19,45]. Recent GWAS findings have indicated that variants of the IRF4 gene were associated with the susceptibility to some cancer types, including CLL, HL, NHL, MM and skin cancer [25-27,35]. Given the possible of the IRF4 gene product in the immune response and carcinogenesis, numerous investigators have studied the possible association between the IRF4 polymorphisms and cancer risk, but the results are somewhat inconclusive. Meta-analysis is a powerful statistical method to combine comparable studies to increase the sample size and statistical power, thereby 
Table 2 Main results of pooled ORs and stratification analysis of IRF4 polymorphisms on cancer risk in the meta-analysis

\begin{tabular}{|c|c|c|c|c|c|c|c|c|c|c|c|c|c|c|c|}
\hline \multirow{2}{*}{$\begin{array}{l}\text { rs12203592 } \\
C / T\end{array}$} & \multicolumn{3}{|c|}{ TT vs CC } & \multicolumn{3}{|c|}{ CT vs CC } & \multicolumn{3}{|c|}{ Dominant model } & \multicolumn{3}{|c|}{ Recessive model } & \multicolumn{3}{|c|}{ Additive model } \\
\hline & $\overline{O R}$ & $95 \% \mathrm{Cl}$ & $P^{a}$ & OR & $95 \% \mathrm{Cl}$ & $P^{a}$ & OR & $95 \% \mathrm{Cl}$ & $P^{a}$ & OR & $95 \% \mathrm{Cl}$ & $P^{a}$ & $\overline{O R}$ & $95 \% \mathrm{Cl}$ & $\mathrm{P}^{\mathrm{a}}$ \\
\hline Overall & 1.566 & $(1.087,2.256)^{*}$ & 0.000 & 1.070 & $(0.904,1.266)^{*}$ & 0.000 & 1.135 & $(0.941,1.368)^{*}$ & 0.000 & 1.526 & $(1.107,2.104)^{*}$ & 0.001 & 1.168 & $(0.981,1.392)^{*}$ & 0.000 \\
\hline \multicolumn{16}{|c|}{ Source of controls } \\
\hline PB & 0.933 & $(0.672,1.295)$ & 0.403 & 0.904 & $(0.793,1.031)$ & 0.320 & 0.907 & $(0.799,1.029)$ & 0.265 & 0.971 & $(0.701,1.345)$ & 0.420 & 0.926 & $(0.830,1.033)$ & 0.215 \\
\hline$H B$ & 2.094 & $(1.314,3.336)^{*}$ & 0.000 & 1.203 & $(0.936,1.547)^{*}$ & 0.000 & 1.314 & $(1.002,1.723)^{*}$ & 0.000 & 1.959 & $(1.310,2.931)^{*}$ & 0.003 & 1.351 & $(1.058,1.725)^{*}$ & 0.000 \\
\hline \multicolumn{16}{|l|}{ Cancer type } \\
\hline Skin cancer & 1.808 & $(1.127,2.900)^{*}$ & 0.000 & 1.130 & $(0.890,1.435)^{*}$ & 0.000 & 1.217 & $(0.935,1.584)^{*}$ & 0.000 & 1.728 & $(1.145,2.608)^{*}$ & 0.000 & 1.253 & $(0.983,1.596)^{*}$ & 0.000 \\
\hline Melanoma & 1.315 & $(0.624,2.770)^{*}$ & 0.000 & 0.957 & $(0.724,1.265)^{*}$ & 0.009 & 1.011 & $(0.715,1.431)^{*}$ & 0.000 & 1.321 & $(0.684,2.552)^{*}$ & 0.001 & 1.057 & $(0.747,1.497)^{*}$ & 0.000 \\
\hline $\mathrm{BCC}$ & 2.511 & $(1.630,3.867)$ & 0.430 & 1.085 & $(0.861,1.368)$ & 0.668 & 1.245 & $(1.004,1.543)$ & 0.996 & 2.451 & $(1.600,3.755)$ & 0.383 & 1.352 & $(1.131,1.617)$ & 0.644 \\
\hline SCC & 2.520 & $(1.598,3.974)$ & 0.703 & 1.651 & $(1.330,2.049)$ & 0.208 & 1.743 & $(1.418,2.143)$ & 0.207 & 2.120 & $(1.354,3.318)$ & 0.901 & 1.643 & $(1.385,1.949)$ & 0.303 \\
\hline NHL & 1.074 & $(0.734,1.571)$ & 0.677 & 0.948 & $(0.820,1.096)$ & 0.545 & 0.960 & $(0.834,1.104)$ & 0.734 & 1.103 & $(0.756,1.608)$ & 0.589 & 0.979 & $(0.867,1.106)$ & 0.914 \\
\hline \multicolumn{16}{|l|}{ Ethnicity } \\
\hline Caucasian & 1.808 & $(1.127,2.900)^{*}$ & 0.000 & 1.130 & $(0.890,1.435)^{*}$ & 0.000 & 1.135 & $(0.941,1.368)^{*}$ & 0.000 & 1.728 & $(1.145,2.608)^{*}$ & 0.000 & 1.253 & $(0.983,1.596)^{*}$ & 0.000 \\
\hline Mixed & 1.074 & $(0.734,1.571)$ & 0.677 & 0.948 & $(0.820,1.096)$ & 0.545 & 0.960 & $(0.834,1.104)$ & 0.734 & 1.103 & $(0.756,1.608)$ & 0.589 & 0.979 & $(0.867,1.106)$ & 0.914 \\
\hline rs872071 & \multicolumn{3}{|c|}{ GG vs $A A$} & \multicolumn{3}{|c|}{ GA vs $A A$} & \multicolumn{3}{|c|}{ Dominant model } & \multicolumn{3}{|c|}{ Recessive model } & \multicolumn{3}{|c|}{ Additive model } \\
\hline $\mathrm{G} / \mathrm{A}$ & $\overline{\mathrm{OR}}$ & $95 \% \mathrm{Cl}$ & $P^{a}$ & OR & $95 \% \mathrm{Cl}$ & $P^{a}$ & $\overline{O R}$ & $95 \% \mathrm{Cl}$ & $P^{a}$ & $\overline{O R}$ & $95 \% \mathrm{Cl}$ & $P^{a}$ & $\overline{\mathrm{OR}}$ & $95 \% \mathrm{Cl}$ & $P^{a}$ \\
\hline Overall & 1.805 & $(1.402,2.323)^{*}$ & 0.002 & 1.427 & $(1.203,1.692)^{*}$ & 0.034 & 1.556 & $(1.281,1.891)^{*}$ & 0.003 & 1.432 & $(1.293,1.587)$ & 0.109 & 1.349 & $(1.201,1.515)^{*}$ & 0.002 \\
\hline \multicolumn{16}{|c|}{ Source of controls } \\
\hline PB & 1.767 & $(1.244,2.511)^{*}$ & 0.003 & 1.369 & $(1.041,1.801)^{*}$ & 0.018 & 1.478 & $(1.278,1.708)^{*}$ & 0.003 & 1.443 & $(1.270,1.639)$ & 0.070 & 1.329 & $(1.116,1.582)^{*}$ & 0.002 \\
\hline HB & 1.884 & $(1.212,2.930)^{*}$ & 0.037 & 1.446 & $(1.247,1.678)$ & 0.255 & 1.637 & $(1.219,2.198)$ & 0.058 & 1.414 & $(1.191,1.678)$ & 0.215 & 1.333 & $(1.213,1.465)$ & 0.069 \\
\hline \multicolumn{16}{|l|}{ Cancer type } \\
\hline CLL & 2.424 & $(1.995,2.945)$ & 0.841 & 1.752 & $(1.466,2.093)$ & 0.825 & 1.982 & $(1.674,2.346)$ & 0.968 & 1.646 & $(1.431,1.892)$ & 0.445 & 1.543 & $(1.407,1.692)$ & 0.647 \\
\hline Lymphoma & 1.396 & $(1.123,1.735)$ & 0.614 & 1.279 & $(1.103,1.483)$ & 0.472 & 1.308 & $(1.135,1.507)$ & 0.579 & 1.245 & $(1.039,1.491)$ & 0.754 & 1.206 & $(1.095,1.328)$ & 0.764 \\
\hline \multicolumn{16}{|l|}{ Ethnicity } \\
\hline Caucasian & 1.844 & $(1.377,2.470)^{*}$ & 0.003 & 1.418 & $(1.124,1.787)^{*}$ & 0.019 & 1.567 & $(1.214,2.023)^{*}$ & 0.003 & 1.463 & $(1.311,1.633)$ & 0.115 & 1.350 & $(1.174,1.554)^{*}$ & 0.003 \\
\hline Asian & 1.451 & $(1.072,1.965)$ & 0.075 & 1.380 & $(1.164,1.636)$ & 0.205 & 1.390 & $(1.180,1.637)$ & 0.109 & 1.233 & $(0.924,1.646)$ & 0.167 & 1.256 & $(1.110,1.420)$ & 0.071 \\
\hline
\end{tabular}

PB: population based; $H B$ : hospital based; Bold data represent the positive results.
*Random-effects model was used when $P$ value for heterogeneity test $<0.05$; otherwise, fix-effects model was used.

ap value of Q-test for heterogeneity test; BCC: Basal cell carcinoma; SCC: Squamous cell carcinoma; HL: Hodgkin lymphoma; NHL: Non-Hodgkin lymphoma; MM: Multiple myeloma; CLL: Chronic lymphocytic leukaemia. 


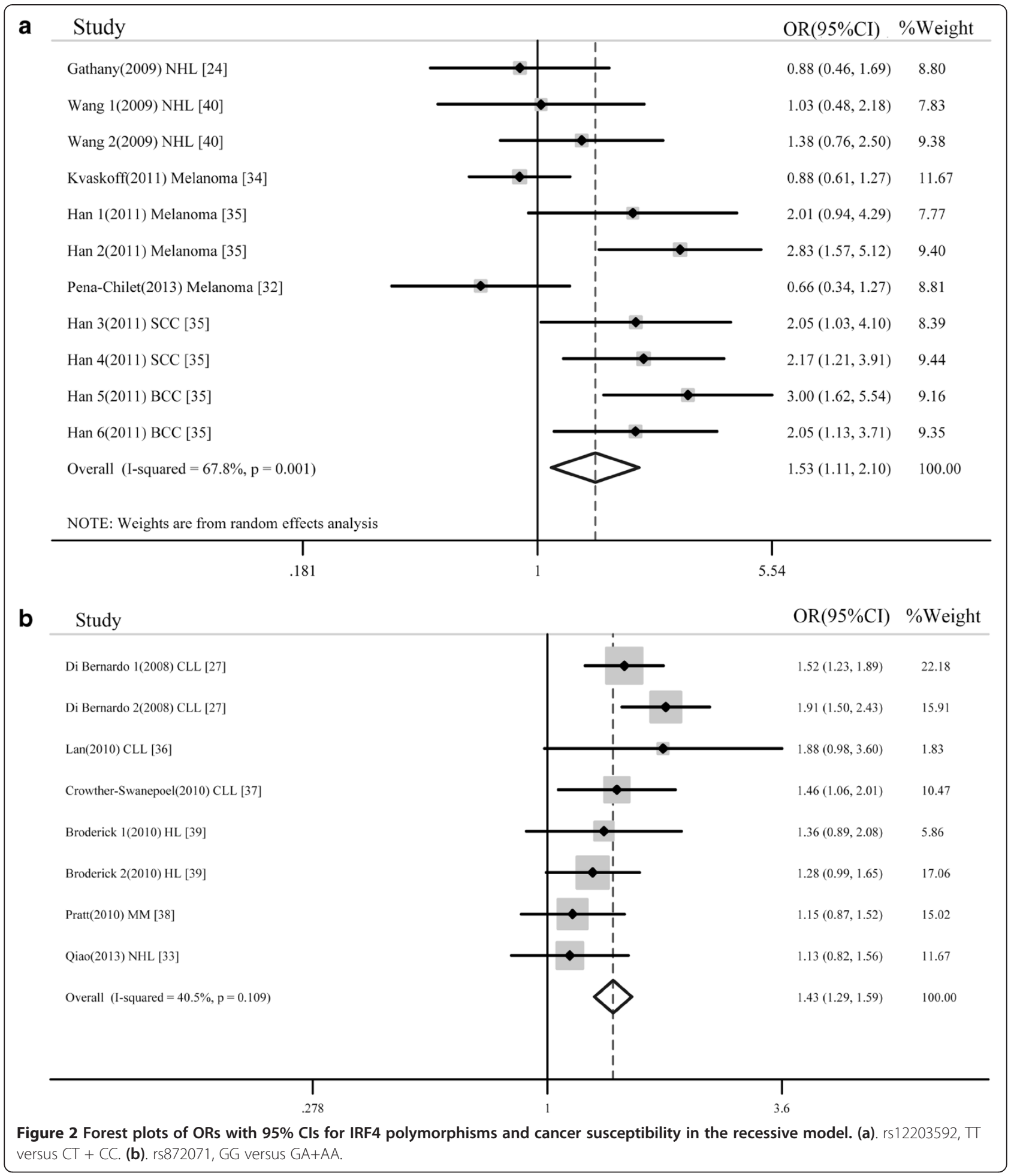

allowing a more compelling result to be drawn [46]. These advantages encouraged us to conduct this metaanalysis of all published articles investigating the association between IRF4 gene polymorphisms and cancer risk. To our knowledge, this is the first comprehensive meta-analysis examining the association of two common 6p25 variations (rs12203592 and rs872071) and skin cancer and haematological malignancies susceptibility.

In this meta-analysis, we included 11 eligible articles comprised of 19 case-control or cohort studies to explore the association between the rs12203592 and rs872071 IRF4 polymorphisms and skin cancer and haematological 


\section{a}

\section{| Lower CI Limit $\quad$ Estimate Upper CI Limit}

Gathany(2009) NHL [24]

Wang 1(2009) NHL [40]

Wang 2(2009) NHL [40]

Kvaskoff(2011) Melanoma [34]

Han 1(2011) Melanoma [35]

Han 2(2011) Melanoma [35]

Pena-Chilet(2013) Melanoma [32]

Han 3(2011) SCC [35]

Han 4(2011) SCC [35]

Han 5(2011) BCC [35]

Han 6(2011) BCC [35]

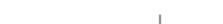

1.011 .09

b

b

Di Bernardo 1(2008) CLL [27]

Di Bernardo 2(2008) CLL [27]

Lan(2010) CLL [36]

Crowther-Swanepoel(2010) CLL [37]

Broderick 1(2010) HL [39]

Broderick 2(2010) HL [39]

| Lower CI Limit $\bigcirc$ Estimate

Upper CI Limit
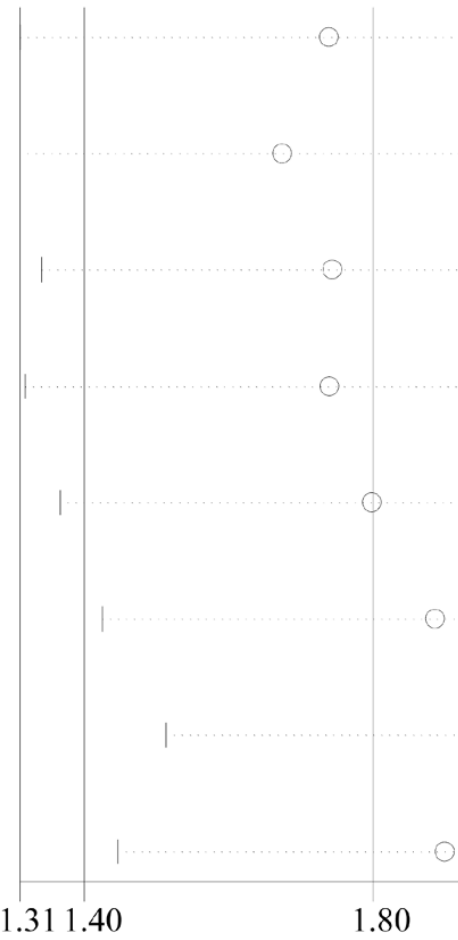

32

Figure 3 Results of the sensitivity analysis examining the association between the IRF4 and cancer risk polymorphisms and cancer risk in homozygote comparison model. (a). rs12203592, TT versus CC. (b). rs872071, GG versus AA. 
malignancies risk. We also performed subgroup analyses stratified by cancer type, ethnicity and source of controls. With respect to the rs12203592 polymorphism, 4901 cases and 5808 controls were included in the current metaanalysis. The pooled analyses suggested a significant association between the rs12203592 polymorphism and cancer susceptibility. In the subgroup analysis based on cancer type, a significant association was observed between this polymorphism and cancer risk exclusively in the skin cancer subgroup. However, no significant association between the rs12203592 polymorphism and NHL was found, indicating that the polymorphism may not be an independent risk factor for the development of NHL. When stratifying for ethnicity, a significant association was observed in Caucasian populations but not in other populations, suggesting genetic diversity among different ethnicities. Additionally, after stratification based on the source of controls, significantly increased risks were found in the hospital-based studies but not in the population-based studies. For the rs 872071 polymorphism, 3108 cases and 8300 controls were included. Overall, there was evidence of an association between an increased risk of haematological malignancies and the rs872071 polymorphism in all genetic models when all of the eligible studies were pooled into the meta-analysis. In the subgroup analyses by cancer type and source of controls, an increased haematological malignancies risk was also observed in all genetic models. When stratified by ethnicity, a significantly increased risk was also observed for Asian populations in all of the genetic models except for the recessive model.

Heterogeneity is a potential problem when explaining the results of all meta-analyses. In the current study, the Q-test and $I^{2}$ statistic were performed to test the significance of heterogeneity. For the rs 12203592 polymorphism, significant heterogeneity was found in all comparison models. When stratified according to cancer type, ethnicity and source of controls, significant heterogeneity reduced or disappeared. For the rs872071 polymorphism, significant heterogeneity was detected in the overall comparisons. After subgroup analysis by cancer type, the heterogeneity was effectively decreased or removed. However, significant heterogeneity still existed Caucasian populations in certain genetic models when stratified according to ethnicity. This finding could be attributed to the fact that different genetic backgrounds and environments exist among different ethnicities and individuals. When stratified for the source of controls, significant heterogeneity still existed in some genetic models for the populationbased studies. In this meta-analysis, the Begg's funnel plot and Egger's test were calculated to evaluate publication bias. Both the shape of the funnel plots and statistical results did not suggest publication bias. We also performed sensitivity analysis that indicated the results were reliable.
Several limitations in our meta-analysis should be acknowledged. First, the meta-analysis was based on the aggregation of published studies; unpublished data, ongoing studies and published articles were excluded. Studies with negative findings may have biased our results. Second, the number of cases and controls and small sample sizes, which could potentially influence the overall outcome, limited this meta-analysis. Third, most of the enrolled subjects were Caucasians and Asians; the populations of other races were under-represented. Fourth, due to the deficient adjusted data, we computed raw relative risks (RRs) from frequency distributions reported in the original publications, so our analyses are not adjusted for the main risk factors of both skin cancer and haematological malignancies. In addition, cancer is a complex disease with a multifactorial aetiology. Lack of original data for gene-gene and gene-environment interactions limited our further evaluation. Despite these limitations, the advantages of our meta-analysis should also be noted. First, studies that satisfactorily met our selection criteria were included in the present metaanalysis. The substantial number of cases and controls pooled from the different studies significantly increased the statistical power of the analysis. Second, the distribution of genotypes in the controls was in agreement with Hardy-Weinberg equilibrium $(P>0.05)$ for all studies. Third, the results of the Funnel plot and Egger's test detected no publication bias, indicating that the pooled result is reliable.

\section{Conclusions}

The evidence from the present meta-analysis supports the notion that both the rs12203592 and rs872071 IRF4 gene polymorphisms are associated with an individual's susceptibility to skin cancer and haematological malignancies. The effect of the rs12203592 polymorphism on cancer is particularly prominent among Caucasians; however, no significant association with cancer risk was demonstrated in the NHL subgroup. Based on the limitations of the present study listed above, further functional studies between these polymorphisms and cancer risk are warranted.

\section{Abbreviations \\ IRF4: Interferon regulatory factor 4; HL: Hodgkin lymphoma; NHL: Non-Hodgkin lymphoma; MM: Multiple myeloma; CLL: Chronic lymphocytic leukaemia; BCC: Basal cell carcinoma; SCC: Squamous cell carcinoma; PB: Population based; HB: Hospital based; OR: Odd ratio; Cl: Confidence interval.}

\section{Competing interests}

The authors declare that they are no competing interests.

\section{Authors' contributions}

SW, QY participated in collection of data and manuscript preparation. SW, QY and PC performed the statistical analysis. AG, PZ, PC participated in study design and critically revised the manuscript. AG and $P Z$ participated in study design and manuscript preparation. All authors read and approved the final manuscript. 


\section{Acknowledgments}

This work was supported by the National Natural Science Foundation of China (grant No. 81172694); the Grant for China Postdoctoral Science Foundation (No. 20110491451); the Grant for the 135 Key Medical Project of Jiangsu Province (No. XK201117); the practice innovation training program projects for the $2 \mathrm{w}$ Jiangsu College students; and the Priority Academic Program Development of Jiangsu Higher Education Institutions. The funders had no role in study design, data collection and analysis.

\section{Author details}

'Department of Neurosurgery, The First Affiliated Hospital, Nanjing Medical University, Nanjing, China. ${ }^{2}$ State Key Laboratory of Reproductive Medicine, Institute of Toxicology, Nanjing Medical University, Nanjing, China. ${ }^{3}$ Key Laboratory of Modern Toxicology of Ministry of Education, School of Public Health, Nanjing Medical University, Nanjing, China.

Received: 3 September 2013 Accepted: 23 May 2014

Published: 6 June 2014

\section{References}

1. Bredberg A: Cancer: more of polygenic disease and less of multiple mutations? a quantitative viewpoint. Cancer 2011, 117(3):440-445.

2. Pharoah PD, Dunning AM, Ponder BA, Easton DF: Association studies for finding cancer-susceptibility genetic variants. Nat Rev Cancer 2004, 4(11):850-860

3. Gordon R: Skin cancer: an overview of epidemiology and risk factors. Semin Oncol Nurs 2013, 29(3):160-169

4. Toll A, Masferrer E, Hernandez-Ruiz ME, Ferrandiz-Pulido C, Yebenes M, Jaka A, Tuneu A, Jucgla A, Gimeno J, Baro T, Casado B, Gandarillas A Costa I, Mojal S, Pena R, de Herreros AG, Garcia-Patos V, Pujol RM, Hernandez-Munoz I: Epithelial to mesenchymal transition markers are associated with an increased metastatic risk in primary cutaneous squamous cell carcinomas but are attenuated in lymph node metastases. J Dermato/ Sci 2013, 72(2):93-102.

5. Saida M: Melanoma and non-melanoma skin cancers. Gan To Kagaku Ryoho 2013, 40(4):452.

6. Lang D, Mascarenhas JB, Shea CR: Melanocytes, melanocyte stem cells, and melanoma stem cells. Clin Dermatol 2013, 31(2):166-178.

7. Wong CS, Strange RC, Lear JT: Basal cell carcinoma. BMJ 2003, 327(7418):794-798

8. D'Cunha N, Cobos E: An update on hematological malignancies. Tex Med 2010, 106(9):59-63.

9. Mitsiades CS, Anderson KC: Epigenetic modulation in hematologic malignancies: challenges and progress. J Natl Compr Canc Netw 2009, 7(Suppl 8):S1-S12. quiz S14-16.

10. Tohda S: Overview of lymphoid neoplasms in the fourth edition of the WHO classification. Rinsho Byori 2012, 60(6):560-564

11. Sabattini E, Bacci F, Sagramoso C, Pileri SA: WHO classification of tumours of haematopoietic and lymphoid tissues in 2008: an overview. Pathologica 2010, 102(3):83-87.

12. Stevenson FK, Caligaris-Cappio F: Chronic lymphocytic leukemia: revelations from the B-cell receptor. Blood 2004, 103(12):4389-4395.

13. Siegel R, Ward E, Brawley O, Jemal A: Cancer statistics, 2011: the impact of eliminating socioeconomic and racial disparities on premature cancer deaths. CA Cancer J Clin 2011, 61(4):212-236.

14. Muller AM, Ihorst G, Mertelsmann R, Engelhardt M: Epidemiology of non-Hodgkin's lymphoma (NHL): trends, geographic distribution, and etiology. Ann Hematol 2005, 84(1):1-12.

15. Taniguchi T, Ogasawara K, Takaoka A, Tanaka N: IRF family of transcription factors as regulators of host defense. Annu Rev Immunol 2001, 19:623-655

16. Mamane Y, Heylbroeck C, Genin P, Algarte M, Servant MJ, LePage C, DeLuca C, Kwon H, Lin R, Hiscott J: Interferon regulatory factors: the next generation. Gene 1999, 237(1):1-14.

17. Harada $\mathrm{H}$, Taniguchi $\mathrm{T}$, Tanaka N: The role of interferon regulatory factors in the interferon system and cell growth control. Biochimie 1998, 80(8-9):641-650.

18. Tamura T, Yanai H, Savitsky D, Taniguchi T: The IRF family transcription factors in immunity and oncogenesis. Annu Rev Immunol 2008, 26:535-584.
19. Matsuyama T, Grossman A, Mittrucker HW, Siderovski DP, Kiefer F, Kawakami T, Richardson CD, Taniguchi T, Yoshinaga SK, Mak TW: Molecular cloning of LSIRF, a lymphoid-specific member of the interferon regulatory factor family that binds the interferon-stimulated response element (ISRE). Nucleic Acids Res 1995, 23(12):2127-2136

20. Yamagata T, Nishida J, Tanaka S, Sakai R, Mitani K, Yoshida M, Taniguchi T, Yazaki $Y$, Hirai $\mathrm{H}$ : A novel interferon regulatory factor family transcription factor, ICSAT/Pip/LSIRF, that negatively regulates the activity of interferon-regulated genes. Mol Cell Biol 1996, 16(4):1283-1294.

21. Eisenbeis CF, Singh H, Storb U: Pip, a novel IRF family member, is a lymphoid-specific, PU.1-dependent transcriptional activator. Genes Dev 1995, 9(11):1377-1387

22. Yanai $H$, Negishi $H$, Taniguchi $T$ : The IRF family of transcription factors: Inception, impact and implications in oncogenesis. Oncoimmunology 2012, 1(8):1376-1386.

23. Zheng Y, Chaudhry A, Kas A, deRoos P, Kim JM, Chu TT, Corcoran L, Treuting P, Klein U, Rudensky AY: Regulatory T-cell suppressor program co-opts transcription factor IRF4 to control T(H)2 responses. Nature 2009, 458(7236):351-356.

24. Gathany AH, Hartge P, Davis S, Cerhan JR, Severson RK, Cozen W, Rothman $\mathrm{N}$, Chanock SJ, Wang SS: Relationship between interferon regulatory factor 4 genetic polymorphisms, measures of sun sensitivity and risk for non-Hodgkin lymphoma. Cancer Cause Control 2009, 20(8):1291-1302.

25. Bishop DT, Demenais F, lles MM, Harland M, Taylor JC, Corda E, Randerson-Moor J, Aitken JF, Avril MF, Azizi E, Bakker B, Bianchi-Scarrà G, Bressac-de Paillerets B, Calista D, Cannon-Albright LA, Chin-A-Woeng T, Debniak T, Galore-Haskel G, Ghiorzo P, Gut I, Hansson J, Hocevar M, Höiom V, Hopper JL, Ingvar C, Kanetsky PA, Kefford RF, Landi MT, Lang J, Lubiński J, et al: Genome-wide association study identifies three loci associated with melanoma risk. Nat Genet 2009, 41(8):920-925.

26. Brown KM, Macgregor S, Montgomery GW, Craig DW, Zhao ZZ, lyadurai K, Henders AK, Homer N, Campbell MJ, Stark M, Thomas S, Schmid H, Holland EA, Gillanders EM, Duffy DL, Maskiell JA, Jetann J, Ferguson M, Stephan DA, Cust AE, Whiteman D, Green A, Olsson H, Puig S, Ghiorzo P, Hansson J, Demenais F, Goldstein AM, Gruis NA, Elder DE, et al: Common sequence variants on 20q11.22 confer melanoma susceptibility. Nat Genet 2008, 40(7):838-840

27. Di Bernardo MC, Crowther-Swanepoel D, Broderick P, Webb E, Sellick G, Wild R, Sullivan K, Vijayakrishnan J, Wang Y, Pittman AM, Sunter NJ, Hall AG, Dyer MJ, Matutes E, Dearden C, Mainou-Fowler T, Jackson GH, Summerfield G, Harris RJ, Pettitt AR, Hillmen P, Allsup DJ, Bailey JR, Pratt G, Pepper C, Fegan C, Allan JM, Catovsky D, Houlston RS: A genome-wide association study identifies six susceptibility loci for chronic lymphocytic leukemia. Nat Genet 2008, 40(10):1204-1210.

28. Shaffer AL, Emre NC, Lamy L, Ngo VN, Wright G, Xiao W, Powell J, Dave S, Yu X, Zhao H, Zeng Y, Chen B, Epstein J, Staudt LM: IRF4 addiction in multiple myeloma. Nature 2008, 454(7201):226-231.

29. DerSimonian R, Laird N: Meta-analysis in clinical trials. Control Clin Trials 1986, 7(3):177-188.

30. Mantel N, Haenszel W: Statistical aspects of the analysis of data from retrospective studies of disease. J Natl Cancer Inst 1959, 22(4):719-748.

31. Egger M, Davey Smith G, Schneider M, Minder C: Bias in meta-analysis detected by a simple, graphical test. BMJ 1997, 315(7109):629-634

32. Pena-Chilet $M$, Blanquer-Maceiras M, Ibarrola-Villava M, Martinez-Cadenas C, Martin-Gonzalez M, Gomez-Fernandez C, Mayor M, Aviles JA, Lluch A, Ribas G: Genetic variants in PARP1 (rs3219090) and IRF4 (rs12203592) genes associated with melanoma susceptibility in a Spanish population. BMC Cancer 2013, 13:160.

33. Qiao Y, Zhou Y, Wu C, Zhai K, Han X, Chen J, Tian X, Chang J, Lu Z, Zhang B, Yu D, Yao J, Shi Y, Tan W, Lin D: Risk of genome-wide association study-identified genetic variants for non-Hodgkin lymphoma in a Chinese population. Carcinogenesis 2013, 34(7):1516-1519.

34. Kvaskoff M, Whiteman DC, Zhao ZZ, Montgomery GW, Martin NG, Hayward NK, Duffy DL: Polymorphisms in nevus-associated genes MTAP, PLA2G6, and IRF4 and the risk of invasive cutaneous melanoma. Twin Res Hum Genet 2011, 14(5):422-432.

35. Han J, Qureshi AA, Nan H, Zhang J, Song Y, Guo Q, Hunter DJ: A germline variant in the interferon regulatory factor 4 gene as a novel skin cancer risk locus. Cancer Res 2011, 71(5):1533-1539.

36. Lan Q, Au WY, Chanock S, Tse J, Wong KF, Shen M, Siu LP, Yuenger J, Yeager M, Hosgood HD 3rd, Purdue MP, Liang R, Rothman N: Genetic 
susceptibility for chronic lymphocytic leukemia among Chinese in Hong Kong. Eur J Haematol 2010, 85(6):492-495.

37. Crowther-Swanepoel D, Mansouri M, Enjuanes A, Vega A, Smedby KE, Ruiz-Ponte C, Jurlander J, Juliusson G, Montserrat E, Catovsky D, Campo E, Carracedo A, Rosenquist R, Houlston RS: Verification that common variation at 2q37.1, 6p25.3, 11q24.1, 15q23, and 19q13.32 influences chronic lymphocytic leukaemia risk. Br J Haematol 2010, 150(4):473-479.

38. Pratt G, Fenton JA, Allsup D, Fegan C, Morgan GJ, Jackson G, Sunter NJ, Hall AG, Irving JA, Allan JM: A polymorphism in the 3' UTR of IRF4 linked to susceptibility and pathogenesis in chronic lymphocytic leukaemia and Hodgkin lymphoma has limited impact in multiple myeloma. Br J Haematol 2010, 150(3):371-373.

39. Broderick P, Cunningham D, Vijayakrishnan J, Cooke R, Ashworth A, Swerdlow A, Houlston R: IRF4 polymorphism rs872071 and risk of Hodgkin lymphoma. Br J Haematol 2010, 148(3):413-415.

40. Wang SS, Purdue MP, Cerhan JR, Zheng T, Menashe I, Armstrong BK, Lan Q, Hartge P, Kricker A, Zhang Y, Morton LM, Vajdic CM, Holford TR, Severson RK, Grulich A, Leaderer BP, Davis S, Cozen W, Yeager M, Chanock SJ, Chatterjee N, Rothman N: Common gene variants in the tumor necrosis factor (TNF) and TNF receptor superfamilies and NF-kB transcription factors and non-Hodgkin lymphoma risk. PLoS One 2009, 4(4):e5360.

41. Do TN, Ucisik-Akkaya E, Davis CF, Morrison BA, Dorak MT: An intronic polymorphism of IRF4 gene influences gene transcription in vitro and shows a risk association with childhood acute lymphoblastic leukemia in males. Biochim Biophys Acta 2010, 1802(2):292-300.

42. Gualco G, Weiss LM, Bacchi CE: MUM1/IRF4: a review. Appl Immunohistochem Mol Morphol 2010, 18(4):301-310

43. Lu R: Interferon regulatory factor 4 and 8 in B-cell development. Trends Immunol 2008, 29(10):487-492.

44. Klein U, Dalla-Favera R: Germinal centres: role in B-cell physiology and malignancy. Nat Rev Immunol 2008, 8(1):22-33.

45. Sundram U, Harvell JD, Rouse RV, Natkunam Y: Expression of the B-cell proliferation marker MUM1 by melanocytic lesions and comparison with S100, gp100 (HMB45), and MelanA. Mod Pathol 2003, 16(8):802-810.

46. Munafo M: Replication validity of genetic association studies of smoking behavior: what can meta-analytic techniques offer? Nicotine Tob Res 2004, 6(2):381-382.

doi:10.1186/1471-2407-14-410

Cite this article as: Wang et al: Association of interferon regulatory factor 4 gene polymorphisms rs 12203592 and rs872071 with skin cancer and haematological malignancies susceptibility: a meta-analysis of 19 case-control studies. BMC Cancer 2014 14:410

\section{Submit your next manuscript to BioMed Central and take full advantage of:}

- Convenient online submission

- Thorough peer review

- No space constraints or color figure charges

- Immediate publication on acceptance

- Inclusion in PubMed, CAS, Scopus and Google Scholar

- Research which is freely available for redistribution 